\title{
Leadership Style and Perceived Organisational Politics as Predictors of Organisational Commitment among Civil Servants in Osun State
}

\author{
A. K. Fashola \\ Department of Psychology \\ Obafemi Awolowo University \\ Ile-Ife, Nigeria \\ A. A. Akanni \\ Department of Psychology \\ Obafemi Awolowo University \\ Ile-Ife, Nigeria \\ C. O. Ajila \\ Department of Psychology \\ Obafemi Awolowo University \\ Ile-Ife, Nigeria \\ E-mail: cajila2002@yahoo.co.uk
}

Received: July 21, 2016 Accepted: August 31, 2016 Published: September 20, 2016

doi:10.5296/jad.v2i2.10042ＵRL: http://dx.doi.org/10.5296/jad.v2i2.10042

\begin{abstract}
This study examined the predictive roles of leadership styles and perceived organisational politics on organisational commitment among Civil Servant in Osun State. Primary data for the study were collected from a total of 248 Civil Servants in Osun state using the stratified random sampling technique. Three standardized Psychological Scales were used in the study. These were the Supervisors Behaviour Descriptive Questionnaire (SBDQ), Perception of
\end{abstract}




\section{Macrothink}

Journal of Asian Development

ISSN 2377-9594 2016, Vol. 2, No. 2

Organisational Politics Scale (POPS) and Organisational Commitment Questionnaire (OCQ). Data collected were subjected to inferential statistics such as Pearson Moment Correlation and Multiple Regression. Results showed a significant positive relationship between leadership style and organisational commitment among Civil Servants in Osun State (r $(246)=0.31, p<0.05\}$. It also revealed a significant relationship between perceived organisational politics and organisational commitment $\{r=(246)=0.20, p>0.05\}$. It further showed a joint significant relationship among leadership style, perceived organisational politics and organisational commitment $\{\mathrm{F}(2,245)=16.21, \mathrm{p}<0.05\}$. The stepwise multiple regression analysis revealed that $9.4 \%$ variation in organisational commitment is explained by the democratic leadership style, autocratic leadership style and perceived organisational politics $\left\{\mathrm{r}=0.324, \mathrm{r}^{2}(\mathrm{adj})=0.0094, \mathrm{~F}(3,244)=9.514, \mathrm{P}<0.05\right\}$. The study concluded that both leadership style and perceived organisational politics predicted organisational commitment.

Keywords: Leadership Style; Perceived Organisational Politics; Organisational, Commitment; Civil Servants 


\section{Introduction}

Organisational commitment refers to the extent to which an employee develops an attachment and feels a sense of allegiance to his or her employer (The Pennsylvania State University, 2011). This can be described as the psychological bond of an employee to an organisation, and its strength of which depends on the degree of employee involvement, employee loyalty, and belief in the values of the organisation. Commitment has always been believed as the driving force behind a person's success. A person who has committed himself to a task will pursue it until its completion, even if there are few obstacles in the process.

Employee's commitment has offered industrial/organisational psychologist opportunity to identify how the organisation is a psychologically meaningful environment to individual organisation members. Akintayo (2010) noted that one of the best known ways of studying organisation has been to measure employee's commitment. However, indicators of employee commitment are accepting the organisational mission, adopting the organisational culture (values and behaviours), feeling and showing a desire to continued membership in the organisation, and exerting maximum effort to achieve the organisational goals (Atak, 2009). But, Sreejesh and Tavleen (2011) consider commitment towards an organisation as a matter of personal choice, but based on rational judgment.

Employees commitment could be influenced by personal and organisational variables. Personal variables include personality types, values, health status, work-family balance, sense of personal achievement in life and general life satisfaction. Organisational variables include leadeship styles, perceived organisational politics, pay and benefits, perceived fairness in the organisational system, quality of work condition and the job itself. This study considers leadership style and percieved organisational politics as predictors of employee's commitmnet.

Leadership is a process of influencing others' towards realizing their full potential in achieving a value-added, shared vision with passion and integrity (Ngambi, 2011). Thus, a leader is expected to have the ability to make decision rather than carrying out the actions. There are basically three types of leadership styles and each of these seems appropriate at different situations. These are autocratic, democratic and laissez-faire. In an emergency when there is little time to converge on an agreement and where a designated authority has significantly more experience or expertise than the rest of the team, an autocratic leadership style may be most effective. In a highly motivated and aligned team with a homogeneous level of expertise, a more democratic style may be more effective. The style adopted should be the one that will most effectively achieve the objectives of the group while balancing the interests of its individual members. It must also be the one that will encourage members to be more committed to their job.

Perceived organisational politics is another variable of concern in this study. While there is no doubt that internal politics is a common phenomenon in every organisation, very little is known about the nature and boundaries of such politics. An individual's political behaviour may help to formulate his perceptions of the work environment. As suggested by Ogungbamila (2013), uncertainty is the major predictor of 
organisational politics. Employees chose to participate in political behaviours when they view their work environment as political in nature and promoting the self-interests of others from the individuals point of view. Given the situation of scarcity of resources and the perspective that people are self-centered, it seems that no one can avoid the influence of organisational politics.

Political behaviour is not limited to those who hold public positions. It is found in every organisation. Gallagher and Laird (2008) defined perceived organizational politics as an

individual's view which is normally characterized by colleagues and supervisors demonstrating behaviors that are self-serving. Employees perception of organisational politics had been sharpened by globalization via changing technology, changing work culture, changing work cluster, high demands in job, changing life style and changes in mega environment (Danish, 2000).

\subsection{Statement of the Problem}

Studies have been carried out on various aspects of organisational commitment, leadership style and perceived organisational politics. Review of literature revealed that most of such studies have concentrated on leadership styles and organisational commitment (Walumbwa \& Lawler, 2003, Wuestewald and Steinheider, 2006; Adebayo, 2004; Burke, 2003; Lew,2009; Yulk \& Lepsinger, 2005). Scholars have examined the relationship between perceived organisational politics and several aspects of organisational outcomes like job satisfaction, job performance and organisational commitment (Vigoda, Peter \& Zion, 2003; Boldla \& Dannish, 2009). Perceived organisational politics and organisational commitment are widely studied variables in management literature (Vigoda, 2000; Hu, 2010; Bergmann, Lester, De Meuse, \& Grahn, 2011; Jam, Khan, Zaidi \& Muzaffar,2011) which are precursors for the organisation's success. However, very little information is available on the influence of perceived organisational politics on employee's level of organisational commitment. Yet, others have established the link between positive perception of organisational politics as it relates to job satisfaction (Fedor, Maslyn, Farmer, \& Betternhausen, 2008).

However, very little research attention has been given to the link between leadership styles, perceived organisational politics and organisational commitment. Therefore, this study intends to examine whether leadership styles and perceived organisational politics will jointly predict organisational commitment.

\subsection{Objectives of the Study}

The specific objectives of this study are to;

i. examine the dimensions of employee commitment among Civil Servant in Osun State;

ii. assess the relationship between leadership styles and organisational commitment among Civil Servant in Osun State;

iii. examine the relationship between perceived organisational politics and 
organisational commitment among Civil Servant in Osun State; and

iv. ascertain the joint relationship among leadership styles, perceived organisational politics and organisational commitment among Civil Servant in Osun State;

\section{Literature Review}

\subsection{Leadership Style and Organisational Commitment}

Series of studies have been conducted to investigate the relationship between leadership style, perceived organisation politics and organisational commitment. Leadership behaviour has direct impact on the work environment, work outcomes and the general success of the organisation (Kritsonis, 2004). According to Lok and Crawford (2003), previous studies showed that employees' response to leadership behaviour and organisation's values can motivate their actual commitment. Olasupo (2008) in his studies on the relationship between leadership styles and job satisfaction found that there was no support for the relationship between the variables. This result is consistent with that of Madock (2008) who sought for the link between leadership styles and employees' satisfaction.

Majority of the researchers had associated transformational leadership with employee's commitment and job satisfaction and argued that transformational leadership can be the best predictor of employee performance (Raja \& Palanichamy, 2011). Limsila \& Ogunlana (2008) also examined the correlation between leadership styles and subordinates' organisational commitment in construction company, and established that leadership style has a positive relationship with work performance and organisation commitment. Transformational culture boosts both the organisation and the employee's commitment without enforcing extra burden (Schlotz, 2009). Ismail and Yusuf (2009) found a significant positive relation between transformational leadership and organisational commitment. In a related development, Ayinde, Ajila and Akanni (2012) studied the mediating role of psychosocial factors on the impact of downsizing on employees' commitment to work. The result also showed that employee's perception of downsizing was significantly related to psychosocial factors like locus of control and job status.

\subsection{Organisational Politics and Employees' Commitment}

Salami (2008) examined the demographic and psychological factors predicting organisational commitment among industrial workers and found that demographic factors such as age, tenure and education level are associated with organisational commitment. Hu (2010) in his study of "Perceived Organizational Politics and Organisational Commitment: Exploring the Moderating Effect of job security", found a significant negative relationship between perceived organisational politics and affective commitment.

Fuller, Maeler and Hester (2006) argued that the leader's behaviour affects employee job perceptions of organisational politics, which then affect employee attitudes towards the job and performance. Therefore, employees who perceived organisational politics may engage in workplace incivility against perpetrators or beneficiaries of such political behaviours as a pay-back (Ferguson \& Beaver, 2009). Hu (2013) examined the moderating effect of job 
security on the relationship between organisational politics and organisational commitment and established a significant negative relationship between perceived organisational politics and the two dimensions of organisational commitment.

\subsection{Research Hypotheses}

The following hypotheses have been postulated for statistical testing.

1) There will be a significant relationship between leadership style and organisational commitment.

2) There will be a significant relationship between perceived organisational politics and organisational commitment.

3) There will be a joint significant relationship between leadership styles, perceived organisational politics and organisational commitment.

\section{Methods}

The study adopted a correlational research design. The sample size for the study consists of 248 respondents which were selected using stratified sampling technique. The two hundred and forty-eight (248) employees were proportionately selected from various departments in the four ministries, which are Ministry of Finance (45), Ministry of Commerce (61), Ministry of Agriculture (67) and Ministry of Education (75), which represent the sampling frame for the study.

\subsection{Instrument}

The three standardized psychological instruments are Supervisors Behaviour Descriptive Questionnaire (SBDQ), Perception of Organisational Politics Scale (POPS) and Organisation Commitment Scale.

Supervisory Behaviour Descriptive Scale: The Supervisory Behaviour Descriptive Questionnaire (SBDQ) developed by Fleishman (1953) was employed to measure Leadership Styles. It is a 48- item scale with responses to each items on a five point Likert Scale ranging from $1=$ never, $2=$ seldom, $3=$ occasionally, $4=$ often and $5=$ always.

Fleishman (1953) reported a Spearman Brown's reliability coefficient of .98 with test retest reliability coefficient of .87 for democratic leadership and Spearman Brown's reliability coefficient of .78 with test-retest reliability coefficient of .75 for autocratic leadership style. Concurrent validity coefficient of .14 for democratic leadership style and .34 for autocratic style was obtained by Ejimofor (1987).

Organisational Commitment scale (OCS): The organisation commitment questionnaire developed by Meyer \& Allen (1997) was used to measure organisation commitment. It is an 18-item inventory consisting of three components which are; affective with 6-items, continuance with 6- items and normative with 6-items. Participants are rated on 5-Likert scale from strongly disagree to strongly agree with item phrasing as "I would be very happy to spend the rest of my career with this organisation" (affective), "right now, staying with my 
organisation is a matter of necessity as much as desire" (continuance) and "I do not feel any obligation to remain with my current employer" (normative). Meyer \& Allen (1990) examination of the relationship among the three dimensions of commitment scales revealed that the continuance commitment scale was relatively independent, affective $(p<.001, r=.06)$ and normative $(\mathrm{p}<.001, \mathrm{r}=.14)$, but the correlations between the affective and normative scales were statistically significant and relatively strong $(\mathrm{p}<.001, \mathrm{r}=.54)$. A high rate of reliability of .87 for affective, .75 for continuance and .79 for normative. Cohen (1996) also discover alphas of .79 for affective, .69 for continuance and .65 for normative. Finally, Meyer et al. (1997) performed a meta-analysis of studies of people who had sought permission to use the OCQ during the last 15 years as well as from computer database dating back to 1985 . Ayinde (2011) reported an Alpha coefficient of 0.53 for Nigerian sample.

Perceived Organisational Politics Scale: The perception of organisational politics scale (POPS) developed by Kacmar \& Carlson (1997) was used in measuring perceived organisational politics. It is a 15-items scale, with responses to each scale on a five point likert format ranging from $1=$ strongly agree , 2 = Agree, $3=$ disagree, $4=$ strongly disagree, $5=$ don't know.

The scale was validated with consistent factor analysis (CFA) and it reported structural and factorial validation of comparative fit index $(\mathrm{CFI}=.90)$, goodness of fit index (GFI $=.88)$ and root mean square errors of approximation (RMSEA $=<.05$ ). Kacmar \& Carlson reported internal consistency reliability of Cronbach alpha of 0.88 . Ladebo (2005) reported a cronbach's Alpha of .79 and Ogungbamila (2013) also reported a cronbach's Alpha of .81using Nigerian sample.

\section{Results}

Table 4.1. Descriptive statistics on dimension of organisational commitment

\begin{tabular}{llll}
\hline Dimensions & N & Mean & SD \\
\hline Affective & 248 & 20.75 & 4.95 \\
Continuance & 248 & 19.91 & 3.70 \\
Normative & 248 & 16.91 & 4.16 \\
\hline
\end{tabular}

From Table 4.1, above the result shows that affective dimension of organisational commitment have the highest mean score and standard deviation (20.95 and 4.9), followed by continuance dimension with a mean and standard deviation of (19.9 and 3.70), while the normative dimension have the least mean score of (16.9). The finding implies that employees are higher on affective dimension of organisational commitment than continuance and normative.

\subsection{Hypothesis Testing}

Hypothesis One: The first hypothesis states that there will be a significant relationship between leadership style and organisation commitment.

The Pearson Product Moment Correlation (PPMC) was employed to analyse the data. The 
analysis involves subjecting the respondent composite scores on leadership style and their corresponding composite scores on organisational commitment to a test of relationship. The result is summarised and presented in Table 4.3.

Table 4.2. PPMC analysis showing relationship between Leadership style and Organisational commitment

\begin{tabular}{clllll}
\hline Variables & $N$ & $r$ & $r$-square & $D f$ & $p$-val \\
\hline Leadership style \& commitment & 248 & 0.31 & 0.09 & 246 & 0.0001 \\
\hline
\end{tabular}

$\{\mathbf{r}(246)=0.31, p=0.0001\}$

Table 4.3. Correlational matrix showing relationship between leadership style and organisational commitment

\begin{tabular}{llll}
\hline Variables & $(1)$ & $(2)$ & $(3)$ \\
\hline Democratic (1) & 1 & & \\
Autocratic (2) & $-.437^{* *}$ & 1 & \\
Commitment (3) & $.259^{* *}$ & $-.204^{* *}$ & 1 \\
\hline
\end{tabular}

Results from Table 4.2 showed a statistical significant positive relationship between leadership style and organisational commitment $\{\mathrm{r}(246)=0.31, \mathrm{p}=0.0001\}$. This suggests that there is a significant positive relationship between leadership style and organisational commitment among civil servant in Osun-State. That is, when leadership improves civil servants in Osun state gets more committed to job.

From Table 4.3, the leadership style is further broken down into two, it is found that democratic leadership styles has a significant positive correlation with organisational commitment $\{\mathrm{r}(246)=0.259, \mathrm{p}=0.0001\}$. However, there is significant inverse relationship between Autocratic Leadership style and organisational commitment $\{r(246)=-.204$, $\mathrm{p}=0.001\}$.

The analysis suggests that among Osun-State Civil servants, there is significant negative relationship between autocratic leadership style and organisational commitment.

\subsection{Hypothesis Two}

The second hypothesis state that there will be a significant relationship between perceived organisational politics and organisational commitment.

To test the hypothesis, The Pearson Product Moment Correlation (PPMC) statistical tool was used. Respondent scores on perceived organisational politics and their corresponding scores on organisational commitment were subjected to relationship test. The results of the analysis are presented in Table 4.4 . 
Table 4.4. PPMC analysis showing relationship between perceived organisational politics and organisational commitment

\begin{tabular}{llllll}
\hline Variables & $N$ & $R$ & r-square & $d f$ & $p$-val \\
\hline $\begin{array}{l}\text { Perceived organisation Politics } \\
\text { \& Commitment }\end{array}$ & 248 & 0.20 & 0.04 & 246 & 0.001 \\
\hline
\end{tabular}

$\{\mathbf{r}(246)=0.20, p=0.001\}$

Results from Table 4.4 shows that there is a statistical significant relationship between organisational politics and organisational commitment $\{\mathrm{r}(246)=0.20, \mathrm{p}=0.001\}$. The analysis shows that among civil servants in Osun-State, perceived organisational politics is positively related to organisational commitment. The alternate hypothesis which state that there will be significant relationship between Perceived organisational politics and organisational commitment was therefore accepted.

\subsection{Hypothesis Three}

The third hypothesis postulates that there will be a joint significant relationship between leadership styles, and perceived organisational politics and organisational commitment.

The data on hypothesis three were analysed using a multiple regression analysis. In this analysis, the predictor variables are democratic leadership styles, autocratic leadership style and organisational politics while the outcome variable is organisational commitment. The summary of the analysis is presented in table 4.5 .

Table 4.5. Summary Table of Multiple Regression analysis of Leadership Style, Perceived Organisational Politics and Organisational Commitment

\begin{tabular}{lllllll}
\hline Variable & Beta & $\boldsymbol{T}$ & $\boldsymbol{P}$ & $\boldsymbol{R}$-square & $\boldsymbol{F}$ & $\boldsymbol{P}$-Val \\
\hline Constant & 32.440 & 12.083 & .000 & $\mathbf{0 . 1 1 7}$ & $\mathbf{1 6 . 2 0 7}$ & $\mathbf{0 . 0 0 0 1}$ \\
Leadership Style & .073 & 4.595 & .000 & & & \\
Organisational politics & .091 & 2.527 & .012 & & & \\
\hline
\end{tabular}

$\left\{\boldsymbol{F}(2,245)=16.207, p=0.0001, R^{2}=0.117, R=0.342, R\right.$ - Adjusted $\left.=0.110\right\}$

From the multiple regression table 4.5, it is observed that there is joint significant relationship between leadership styles, perceived organisational politics and organisational commitment $\left\{F(2,245)=16.207, p=0.0001, R^{2}=0.117, R=0.342, R\right.$-Adjusted $\left.=0.110\right\}$. The table further shows that leadership style has (beta $=0.073, t=4.595, p<0.05)$, which shows that leadership style is a significant predictor of organisational commitment and perceived organisational politics was also found to be a significant independent predictor of organisational commitment (beta $=0.091, t=2.527 p<0.05$ ). The alternate hypothesis which states that there 
will be a significant joint relationship between leadership styles, perceived organisational politics and organisational commitment was accepted.

In other to ascertain the relative contribution of each of the variables, leadership style, perceived organisational politics and organisational commitment, a stepwise regression analysis was undertaken. Results are as shown in Table 4.7.

Table 4.6. Model Summary of the stepwise Hierarchical Multiple Regression Analysis for the contribution of Democratic leadership styles, autocratic leadership styles and organisational politics on prediction of organisational commitment

\begin{tabular}{llllllllll}
\hline Variables & $\mathbf{R}$ & $\mathbf{R}^{\mathbf{2}}$ & Adjusted $\mathbf{R}^{\mathbf{2}}$ & Std. of the estimate & \multicolumn{2}{l}{ Change Statistics } & & \\
\cline { 6 - 9 } & & & & & & $\mathbf{R}^{\mathbf{2}}$ change & F-value & df & p-val \\
\hline $\mathbf{1}$ & 0.259 & 0.067 & 0.063 & 4.542 & 0.067 & 17.619 & 1,246 & 0.0001 \\
$\mathbf{2}$ & 0.278 & 0.077 & 0.070 & 4.526 & 0.010 & 10.226 & 2,245 & 0.0001 \\
$\mathbf{3}$ & 0.324 & 0.105 & 0.094 & 4.467 & 0.028 & 9.514 & 3,244 & 0.0001 \\
\hline
\end{tabular}

1 Predictors (constant); Democratic leadership styles

2 Predictors (constant); Democratic and Autocratic leadership styles

3 Predictors (constant); Democratic, Autocratic leadership styles and organisational politics

The result of step wise hierarchical multiple regression presented in table 4.6: suggest that when democratic leadership style was introduced into the regression model, a significant independent prediction was observed on organisational commitment among Civil servants in Osun-State $\left(R=0.26, R^{2}=0.07, R^{2}(a d j)=0.06, F(1,246)=17.62, p<0.05\right)$. The results suggest that $6.7 \%$ variation in dependent variable (organisational commitment) is explained by the independent variable, democratic leadership styles. Furthermore, when the autocratic leadership styles was introduced into the regression model, a significant joint prediction of democratic and autocratic leadership styles on organisational commitment $(R=0.278$, $R^{2}=0.077, R^{2}($ adj $\left.)=0.070, F(2,245)=10.226, p<0.05\right)$ was observed. The democratic and autocratic leadership styles explained $7.7 \%$ variance in organisational commitment. Finally when organisational politics were introduced into the regression model, there was a significant joint prediction of democratic, autocratic leadership styles and organisational politics on organisational commitment $\left(R=0.324, R^{2}=0.105, R^{2}\right.$ (adj) $=0.094, F(3,244)$ $=9.514, p<0.05)$. The table suggest that $9.4 \%$ variation in organisational commitment is explained by the Democratic leadership style, autocratic leadership styles and organisational politics.

\section{Discussion}

\subsection{Discussion of Findings}

Findings from the first hypothesis states that there will be significant relationship between 
leadership style and employees commitment. The result showed a significant positive relationship between leadership styles and employees commitment revealed. This result is consistent with the findings of Limsila and Ogunlana (2008) who examined the correlation between leadership style and subordinates' organisation commitment in construction company. The analysis revealed that leadership style has a positive relationship with organisation commitment. The leadership style was further broken down into two dimensions and it was analyzed with correlational matrix. The correlational matrix showed a relationship between democratic leadership style and organisational commitment and autocratic leadership style and organisational commitment. The result of the analysis showed that democratic leadership has a significant positive relationship with organisational commitment, while autocratic and organisational commitment reported an inverse relationship. This showed that the type of behaviour a leader exhibits in a work settings have implication on the employees' level of commitment. This finding is also in support of John and Maxwell (2014) where they reported a significant positive relationship between democratic leadership style and organisational commitment. By implication, it can be deduced that democratic leadership style is associated with high level of employee commitment than the autocratic leadership.

The second hypothesis states that there will be a significant relationship between perceived organisational politics and organisational commitment. The result obtained from the analysis showed that among Civil Servants in Osun State, perceived organisational politics is related to organisational commitment. This is in agreement with the findings of Okpara (2004) which concluded that when employees are satisfied with their job as well as their organisational environment and leadership, they will be more committed to their organisation. Plausible explanation for this might not be unconnected with the fact that Civil Servants in Osun State, like their counterpart in other states of Nigeria, use organisational politics to acquire and enhance their preferred outcomes in a situation in which uncertainty exists. There are scarce resources (both materially and human) in the State and non programmed decision situation that involve ambiguous circumstances which ultimately give ample opportunity for political maneuvering. Furthermore, the significant relationship between perceived organisational politics and organisational commitment can be explained along Moorhead \& Griffin's (2004) view that political behaviour is an integral part of most government functions. The environment in which Civil Servants in Osun State work contribute greatly to the practice of political behaviour.

Hypotheses three states that there will be a joint significant relationship between leadership style, perceived organisational politics and organisational commitment. It was observed from the result of the data analysis that both leadership style and perceived organisational politics have joint significant relationship with organisational commitment. This finding is in agreement with that of Burke (2003) who asserted that the basic determinants of organisational commitment among employees are leadership behaviour and perceived politics. Plausible explanation for this could be that the kinds of leadership style displayed by various Departmental heads are fair enough to discourage dysfunctional political behaviour. Since political behaviour can serve both ethical and unethical purposes, a leader that is concerned about the ethics of an impending behaviour should know whether ethical considerations are 
part of such behaviour and consequently the psychological state that binds the employee to the organisation.

\subsection{Implication of the Study}

Management should create a working environment that have appropriate orientation about the essence and importance of good leadership, so as to be able to enhance subordinates commitment to work.

Supervisors must take appropriate steps to minimize the potentially dysfunctional consequences of political behaviour.

Employees should try as much as possible to do away with behaviours that can be easily taken as political and threat to their stay in the organisation.

\section{Conclusion}

From the analysis of data collected and interpretation of results, the study concluded that employees placed higher value on affective dimension of organisational commitment. Both leadership style and perceived organisational politics jointly predict organisational commitment.

\section{References}

Adebayo, D. (2004). Gender in the boss-subordinate relationship: A Nigeria study. Journal ofOrganisation Behaviour. 25(4)515 - 525.

Akintayo, D. I. (2010). Work-Family Role Conflict and Organisation Commitment AmongIndustrial Workers in Nigeria. Journal of Psychology and Counselling, 2(1), 1-8.

Atak, M. (2009). The relation between a learning organisation and organizational commitment. Unpublished doctoral dissertation. Ataturk University, institute of social science.

Ayinde, A. T. (2011). Mediating Role of Psychosocial Factors on the Relationship between Downsizing and Employees' Commitment to Work Among Federal Civil Servants in Nigeria. Journal of Social and Psychological Sciences, 4(1), 16-37.

Ayinde, A. T., Ajila, C. O. \& Akanni, A. A. (2012). Locus of control and Job status as mediators of employees' perception of Downsizing and organisational commitment I selected ministries and parastatals in Nigeria. Research on Humanity and Social Sciences, 2(8), 65-73.

Bergmann, T. J., Lester, S. W., De Meuse, K. P., \& Grahn, J. L. (2011). Integrating the three domains of employee commitment: an exploratory study. Journal of Applied Business Research, 1(4), 15-26.

Bodla, M. A., \& Danish, R. Q. (2009). Politics and workplace: An empirical examination of The relationship between perceived organisational politics and work performance. Asian Journal of Management, 16(1), 44-62

Cohen, A., \& Keren, D. (1996). Organisational commitment and cultural values: Examining 
their relationship and their mutual effect on in-role performance and organizational citizenship behaviour. Group \& Organisation Management, 33, 425-452.

Danish, R. Q. (2000). The perception of organisation politics and work performance. The International Journal of Knowledge, Culture and Change Management, 8(4), 123-131.S.

Fedor, D., Maslyn, J., Farmer, S., \& Bettenhausen, K. (2008). The contribution of positive politics to the prediction of employee reactions. Journal of Applied Social Psychology, 38, 76-96.

Ferguson, C.J., \& Bakare, K.M. (2009). The genetic origin of extreme violent. Aggression and violent behaviour, 14, 286-294.

Fleishman, E. A. (1953). The description of supervisory behavior. Journal of Applied Psycholoy, 37, 1-6.

Fuller, J. B., Marler, L. E., \& Hester. K. (2006). Promoting felt responsibility for constructive change and proactive behavior: Exploring aspects of an elaborated model of work design.Journal Organisational Behaviour, 27, 1089-1120.

Gallagher, V. C., \& Laird, M. D. (2008). The Combined Effect of Political Skill and Political Decision Making on Job Satisfaction1. Journal of Applied Social Psychology, 38(9), 2336-2360.

Hu, S. (2010), Perceived Organizational Politics and Organizational Commitment: Exploring the Moderating Effect of Job Insecurity. International Conference on Management and Service Science.(MASS).

$\mathrm{Hu}, \mathrm{S}$. (2013). Perceived organisation politics and organisation commitment: Exploring the moderating effect of job security. Retrieved from http:// ieeexplore. Ieee.org/xpl/articleDetails.

Ismail, A. \& Yusuf, M.H. (2009). The relationship between transformational leadership,empowerment and organisation commitment: a mediating test model testing', Journal of Economics, 2(6), 101-110.

Jam, F. A., Khan, T. I., Zaidi, B. H., \& Muzaffar, S. M. (2011). Political skills moderates the relationship between perception of organizational politics and job outcomes. Journal of Educational and Social Research, 1(4), 57-70.

Judge, T. A., Piccolo, R. F., \& Ilies, R. (2004). The forgotten Ones? The Validity of consideration and Initiating Structure in Leadership research. Journal of Applied Psychology, 89(1), 36-51. Cheltenham: Edward Egler.

Kacmar, K. M., \& Carlson, D. S. (1997). Further validation of the perception of politics scale (POPS): a multiple sample investigation. Journal of Management, 23, 627-658.

Kuye, O., \& Sulaiman, A. (2011). Employee Involvement in Decision Making and Firms Performance in the Manufacturing Sector in Nigeria. Serbian Journal of Management, 6(1), 1-15. http://dx.doi.org/10.5937/sjm1101001K. 
Ladebo, O. J. (2005). Effects of work-related attitudes on the intention to leave the profession: An examination of school teachers in Nigeria. Educational Management Administration \& Leadership, 33(3), 355-369.

Lew, T. (2009) 'The Relationships between perceived organisational support, felt obligation, affective organisational commitment and turnover intention of academics working with private higher educational institutions in Malaysia', European Journal of Social Sciences, 9(1), 72-87.

Limsila K., \& Ogunlana S. (2008). Performance and leadership outcome correlates of leadership styles and subordinate commitment. Engineering, Construction and Arhitectural Management, 15(2), 164-184.

Lok, P., \& Crawford, J. (2003). The effect of organisation culture and leadership style on job satisfaction and organisation commitment. Journal of Management Development, 23(3/4), 321- 338 .

Madock, P. E. (2008). Supervisors' nonverbal immediacy behaviour amd their relationship to surbordinates' communication satisfaction, job satisfaction and willingness to collaborate. Paper presented at the national communication Association Convention, San Antonio, Texas.

Ngambi, H. C. (2011). Rare total leadership: Leading with the heart and hands. Juta, Cape Town.

Ogungbamila, B. (2013). Perception of organizational politics and job related negative emotions as predictors of workplace incivility among employees of distressed banks. European Scientific Journal, 9(5), 125-138.

Olasupo, M. O., \& Ajila, C. O. (2010). Relationship between Organisational Culture and Job Satisfaction among Employees of a Manufacturing Company in Nigeria. Ife social sciences review, 23(1), 201-212.

Omolayo, B. O. (2004). Influence of job variables on workers'commitment and satisfaction in four selected Nigerian manufacturing industries. University of Ado-Ekiti.

Pearson, C., Anderson, L., \& Porath, C. (2005). On the nature, consequences and remedies of work place incivility: Academy of Management Review journal, 19(1), 718.

Raja, A., \& Palanichamy, P. (2011). Leadership Styles and it's impact on Organisational Commitment. The Journal of Commerce, 3(4), 15-23.

Rozhan, O. (2008). Organisation Politics: The role of justice, trust and job ambiguity. Singapore Management Review, 14(2), 79-84.

Salami, S.O. (2008). Demographic and Psychological Factors Predicting Organisation Commitment among Industrial Workers. Anthropologist, 10(1), 31-38.

Sreejesh S, Tavleen N (2011). Antecedents and Consequences of Employee loyalty towards the Organization: Empirical Evidence from Indian Software Industry. IJMS, 18(2).. 
The Pennsylvania State University (2011). Work life benefits and organisational commitment. Journal of Public Administration and Policy Reaseach, 3(3) pp. 68-73.

Vigoda, E. (2000). Internal Politics in Public Administration Systems An Empirical Examination of its Relationship with Job Congruence, Organizational Citizenship Behavior, and In-Role Performance. Public personnel management, 29(2), 185-210.

Vigoda-Gadot, E., \& Drory, A. (2006). Handbook of Organisational Politics. Cheltenham, UK: Edward Elgar.

Vigoda-Gadot, E., Peter, V., \& Zion, B. (2003). Developments in Organisational Politics. Cheltenham: Edward Elgar Publishing.

Walumbwa, F., \& Lawler, J. (2003). Building effective organizations: transformational leadership, collectivist orientation, work related attitudes and withdrawal behaviors in three emerging economies. International Journal of Human Resource Management, 14, 10831101.

Wuestewald, T., \& Steinheinder, B. (2006). The changing face of police leadership. Retrieved February 19, 2015, from Criminal Justice Periodicals.

Yuk1. G., \& Lepsinger. R. (2005). Improving performance through flexible leadership. Leadership in Action, 25(4), 20-21, Center for Creative Leadership and Wiley.

\section{Copyright Disclaimer}

Copyright reserved by the authors.

This article is an open-access article distributed under the terms and conditions of the Creative Commons Attribution license (http://creativecommons.org/licenses/by/3.0/). 